\section{Successful intrathecal chemotherapy combined with radiotherapy followed by pomalidomide and low-dose dexamethasone maintenance therapy for a primary plasma cell leukemia patient}

\author{
Yusuke Yamashita, Shinobu Tamura, \\ Takehiro Oiwa, Hiroshi Kobata, Kodai \\ Kuriyama, Toshiki Mushino, Shogo \\ Murata, Hiroki Hosoi, Akinori \\ Nishikawa, Nobuyoshi Hanaoka, \\ Takashi Sonoki \\ Department of Hematology/Oncology, \\ Wakayama Medical University, \\ Wakayama, Japan
}

\section{Abstract}

Primary plasma cell leukemia (PPCL) is a rare aggressive variant of plasma cell disorder and frequently presents with extramedullary disease. Central nervous system (CNS) involvement with PPCL has an extremely poor prognosis. We describe a 46-year-old man with PPCL treated with a combination of lenalidomide, bortezomib, and dexamethasone as induction therapy following upfront allogeneic stem cell transplantation (allo-SCT). Despite achieving a very good partial response, the patient suffered from an isolated CNS relapse 12 months after allo-SCT. He was immediately started on concurrent intrathecal chemotherapy (IT) and cranial irradiation (RT). Subsequently, pomalidomide and low-dose dexamethasone (Pd) were given as maintenance therapy. He has been without CNS recurrence for more than 18 months. Our case suggests that concurrent IT and RT followed by Pd maintenance therapy may be an effective option to control CNS relapse of PPCL after allo-SCT.

\section{Introduction}

Primary plasma cell leukemia (PPCL) is a very aggressive form of plasma cell disorder. ${ }^{1}$ PPCL is very rare, reported in only 4$6 \%$ of patients with multiple myeloma (MM). ${ }^{2,3}$ PPCL is defined as the presence of more than $20 \%$ plasma cells in the peripheral blood and an absolute plasma cell count greater than $2 \times 10^{9} / \mathrm{L}$, without previous evidence of MM. ${ }^{1}$ Consistent with the high tumor burden, extramedullary involvement, such as hepatosplenomegaly, lym- phadenopathy, soft-tissue plasmacytomas, or leptomeningeal infiltration, is more frequent in PPCL than in MM. ${ }^{1}$ Despite the development of new agents, such as proteasome inhibitors or immunomodulatory drugs (IMiDs), for plasma cell disorders, the median overall survival of PPCL is reported to be 12 months. ${ }^{4}$ Although PPCL is difficult to treat, high-dose melphalan followed by autologous stem cell transplantation (auto-SCT) and/or allogeneic stem cell transplantation (allo-SCT) seems to improve outcomes in younger selected patients. ${ }^{5-7}$ However, patients with PPCL who had central nervous system (CNS) relapse after auto- and/or allo-SCT were refractory to various treatments, and had an extremely poor prognosis. ${ }^{7-9}$ We herein present a PPCL patient with CNS relapse after allo-SCT who underwent concurrent intrathecal therapy (IT) and radiotherapy (RT) followed by maintenance therapy with pomalidomide and low-dose dexamethasone $(\mathrm{Pd})$.

\section{Case Report}

A 46-year-old man without a previous significant medical history was referred to our hospital with complaints of anorexia and generalized fatigue. Physical examination revealed slightly pale conjunctivae and bilateral leg edema. Laboratory findings revealed significant abnormalities, including a white blood cell (WBC) count of $19.7 \times 10^{9} / \mathrm{L}$ with $45 \%$ plasma cells, a hemoglobin level of $11.6 \mathrm{~g} / \mathrm{dL}$, a platelet count of $7.0 \times 10^{9} / \mathrm{L}$, a creatinine level of $7.63 \mathrm{mg} / \mathrm{dL}$, and a LDH level of $301 \mathrm{IU} / \mathrm{L}$ (Table 1). On a peripheral blood smear, the plasma cells were medium-sized, with round nuclei, basophilic cytoplasm, and occasional cytoplasmic vacuoles (Figure 1A). The serum IgG level was $75.88 \mathrm{~g} / \mathrm{L}$, and the serum free light chain (FLC) $\mathrm{k} / \lambda$ ratio was 161.11 (Table 1). In this case, a M-component of the IgG-k type was identified by serum protein electrophoresis. Moreover, flow cytometry on the peripheral blood showed that these plasma cells were positive for CD38, CD49e, CD54, CD138 and cytoplasmic kappa light chain. Thus, he was diagnosed with IgG-k PPCL. Later, cytogenetic analysis revealed 46,XY,der(14)? $\mathrm{t}(11 ; 14)(\mathrm{q} 13 ; \mathrm{q} 32)$ in 9 metaphase cells (Figure 1B) and 46,XY in 11 metaphase cells, and a fluorescent in situ hybridization analysis revealed $C C N D 1 / I G H$ gene fusion rearrangement.

The patient was admitted to an intensive care unit (ICU) for continuous hemodiafiltration (CHDF). On the same day, we start-
Correspondence: Shinobu Tamura, Department of Hematology/Oncology, Wakayama Medical University, 811-1 Kimiidera, Wakayama City, Wakayama, 6418509, Japan.

Tel.: +81.73.441.0665 - Fax: +81.73.441.0653 E-mail: stamura@wakayama-med.ac.jp

Key words: Primary plasma cell leukemia, Allogeneic stem cell transplantation, Central nervous system relapse, Pomalidomide

Contributions: YY, ST, TO, HK, KK, TM, SM, $\mathrm{HH}, \mathrm{AN}$ and $\mathrm{NH}$ managed the patients. YY, ST and TS wrote this manuscript.

Conflict of interest: the authors declare no potential conflict of interest.

Reived for publication: 21 November 2016. Revision received: 3 February 2017.

Accepted for publication: 5 February 2017.

This work is licensed under a Creative Commons Attribution-NonCommercial 4.0 International License (CC BY-NC 4.0).

C) Copyright Y. Yamashita et al., 2017

Licensee PAGEPress, Italy

Hematology Reports 2017; 9:6986

doi:10.4081/hr.2017.6986

ed induction therapy with lenalidomide (15 $\mathrm{mg} /$ day orally on days 1-14), bortezomib (1.3 mg/m² subcutaneously on days $1,4,8$, and 11), and low-dose dexamethasone (20 $\mathrm{mg}$ /day orally on days $1,2,4,5,8,9,11$, and 12), also known as RVD induction therapy, each for a 21-day cycle. ${ }^{10}$ Eight days after starting the induction therapy, the circulating plasma cells in the peripheral blood disappeared, and he was transferred from the ICU after withdrawal of CHDF. After a total of 3 cycles of chemotherapy, the laboratory abnormalities markedly subsided, consistent with a very good partial response (VGPR), because serum immunofixation was positive. The patient was discharged from our hospital. He and his family consented to undergo allo-SCT.

At our outpatient department, because of grade 2 peripheral neuropathy, he continued induction therapy with lenalidomide (25 mg/day orally on days 1-14), bortezomib $\left(1.3 \mathrm{mg} / \mathrm{m}^{2}\right.$ subcutaneously on days 1 and 8 ), and dexamethasone (20 $\mathrm{mg}$ /day orally on days 1 and 8) in each 21-day cycle. After a total of 6 courses, allo-SCT was performed with the bone marrow from an unrelated donor (HLA-A one allele mismatch). The conditioning regimen consisted of fludarabine $120 \mathrm{mg} / \mathrm{m}^{2}\left(30 \mathrm{mg} / \mathrm{m}^{2}\right.$ on day $-5,-4,-3$, and -2 ), melphalan $180 \mathrm{mg} / \mathrm{m}^{2}$ $\left(90 \mathrm{mg} / \mathrm{m}^{2}\right.$ on day-4 and -3 ), and rabbit anti- 
thymocyte globulin $2.5 \mathrm{mg} / \mathrm{m}^{2}\left(1.25 \mathrm{mg} / \mathrm{m}^{2}\right.$ on day -2 and -1$)$. For the prevention of graft-versus-host-disease (GvHD), tacrolimus was started from day -1 , and methotrexate was given on days 1,3 , and 6 . We observed neutrophil engraftment on day 13. Complete donor chimerism was detected in the bone marrow on day 29. During this admission, the patient showed no symptoms of acute GvHD. He was discharged without complications 2 months after alloSCT. However, serum immunofixation was positive despite normal IgG and FLC levels; therefore, he was still considered to have a VGPR.

Two months after discharge, the patient developed cervical, mediastinal, and axillary lymphadenopathy. The serum EpsteinBarr virus (EBV) DNA load was $6.4 \times 10^{4}$ copies $/ 10^{6}$ WBCs. He was therefore diagnosed with EBV-associated lymphoproliferative disease and was immediately treated with 2 cycles of rituximab monotherapy, resulting in a complete response. Tacrolimus was discontinued on day 180 , and there was no evidence of chronic GvHD. However, 6 months after allo-SCT, he had marked cytomegalovirus (CMV) antigenemia. He also developed bilateral CMV retinitis, which was successfully treated with intravenous foscarnet.

Our patient suddenly developed headache and vomiting 350 days after alloSCT. We performed a lumbar puncture to suspect CNS relapse quickly. The protein level in the cerebrospinal fluid was 53 $\mathrm{mg} / \mathrm{dL}$, and the glucose level was 55 $\mathrm{mg} / \mathrm{dL} ; 17$ monocytes per microliter were detected. Cytological examination revealed that some of these cells resembled plasma cells (Figure 2A). Polymerase chain reaction for $\mathrm{EBV}, \mathrm{CMV}$, and human herpesvirus-6 was negative. Magnetic resonance imaging (MRI) with gadolinium (Gd) enhancement revealed a small, enhanced nodule in the lateral medulla oblongata (Figure 2B, arrowhead). Enhanced computed tomography (CT) showed no extramedullary tumors. Serum and urinary protein immunofixation electrophoresis were positive despite normal IgG and FLC levels. Moreover, we still observed complete donor chimerism, without leukemic plasma cells, in his bone marrow. These findings were consistent with isolated CNS involvement by PPCL. The patient underwent 4 courses of weekly IT, consisting of methotrexate $15 \mathrm{mg}$, cytarabine $20 \mathrm{mg}$, and prednisolone $40 \mathrm{mg}$ in combination with local cranial RT ( 5 fractions of 2 Gy for a total dose of $10 \mathrm{~Gy}$ ). After this combined treatment, his neurological symptoms resolved and the plasma cells in the cerebrospinal fluid disappeared. To prevent
Table 1. Laboratory data of the patient at the first visit to our hospital.

\section{Complete blood count}

\begin{tabular}{|c|c|c|c|}
\hline White blood cells & $19.7 \times 10^{9} / \mathrm{L}$ & Plasma cell & $45.0 \%$ \\
\hline Neutrophil & $31.0 \%$ & Red blood cells & $3.56 \times 10^{12} / \mathrm{L}$ \\
\hline Myelocyte & $2.0 \%$ & Hemoglobin & $11.6 \mathrm{~g} / \mathrm{dL}$ \\
\hline Lymphocyte & $13.0 \%$ & Hematocrit & $32.3 \%$ \\
\hline Monocyte & $5.0 \%$ & Reticulocytes & $56 \times 10^{9} / \mathrm{L}$ \\
\hline Eosinophil & $4.0 \%$ & MCV & $90.7 \mathrm{fL}$ \\
\hline \multicolumn{4}{|c|}{ Chemistry } \\
\hline Creatinine & $7.63 \mathrm{mg} / \mathrm{dL}$ & Creatine kinase & $377 \mathrm{IU} / \mathrm{L}$ \\
\hline Blood urea nitrogen & $81.2 \mathrm{mg} / \mathrm{dL}$ & Total protein & $11.5 \mathrm{~g} / \mathrm{dL}$ \\
\hline Sodium & $126 \mathrm{mEq} / \mathrm{L}$ & Albumin & $3.6 \mathrm{~g} / \mathrm{dL}$ \\
\hline Potassium & $5.2 \mathrm{mEq} / \mathrm{L}$ & C-reactive protein & $0.03 \mathrm{mg} / \mathrm{dL}$ \\
\hline Chlorine & $93 \mathrm{mEq} / \mathrm{L}$ & Glucose (fasting) & 88 mg/dL \\
\hline Calcium & $14.8 \mathrm{mg} / \mathrm{dL}$ & 2-microglobulin & $28.7 \mathrm{mg} / \mathrm{dL}$ \\
\hline Phosphorus & $5.2 \mathrm{mg} / \mathrm{dL}$ & $\operatorname{Ig} \mathrm{G}$ & $75.88 \mathrm{~g} / \mathrm{L}$ \\
\hline Aspartate transaminase & $55 \mathrm{IU} / \mathrm{L}$ & $\operatorname{IgA}$ & $0.21 \mathrm{~g} / \mathrm{L}$ \\
\hline Alanine transaminase & $46 \mathrm{IU} / \mathrm{L}$ & $\operatorname{Ig} M$ & $<0.05 \mathrm{~g} / \mathrm{L}$ \\
\hline Alkaline phosphatase & $132 \mathrm{IU} / \mathrm{L}$ & Free light $\kappa$ chain & $1450 \mathrm{mg} / \mathrm{dL}$ \\
\hline$\gamma$-glutamyl transpeptidase & $45 \mathrm{IU} / \mathrm{L}$ & Free light $\lambda$ chain & $9.0 \mathrm{mg} / \mathrm{dL}$ \\
\hline Total bilirubin & $0.6 \mathrm{mg} / \mathrm{dL}$ & $\kappa / \lambda$ ratio & 161.11 \\
\hline
\end{tabular}

Lactate dehydrogenase

$301 \mathrm{IU} / \mathrm{L}$

Ig: Immunoglobulin; MCV: mean corpuscular volume
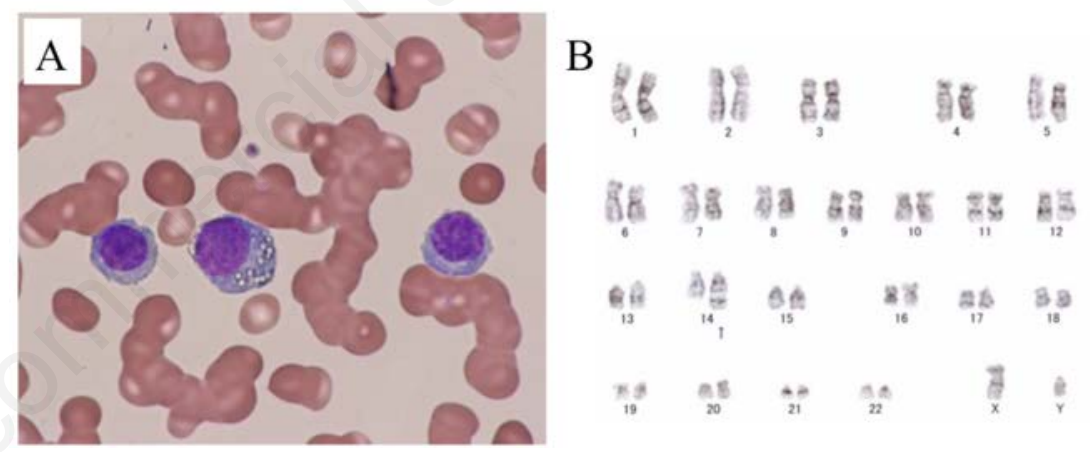

Figure 1. Giemsa stained peripheral blood showing many circulating plasma cells (A). The G-banding chromosomes revealed 46,XY,der(14)?t $(11 ; 14)(q 13 ; q 32)$ in 9 metaphase cells (B).
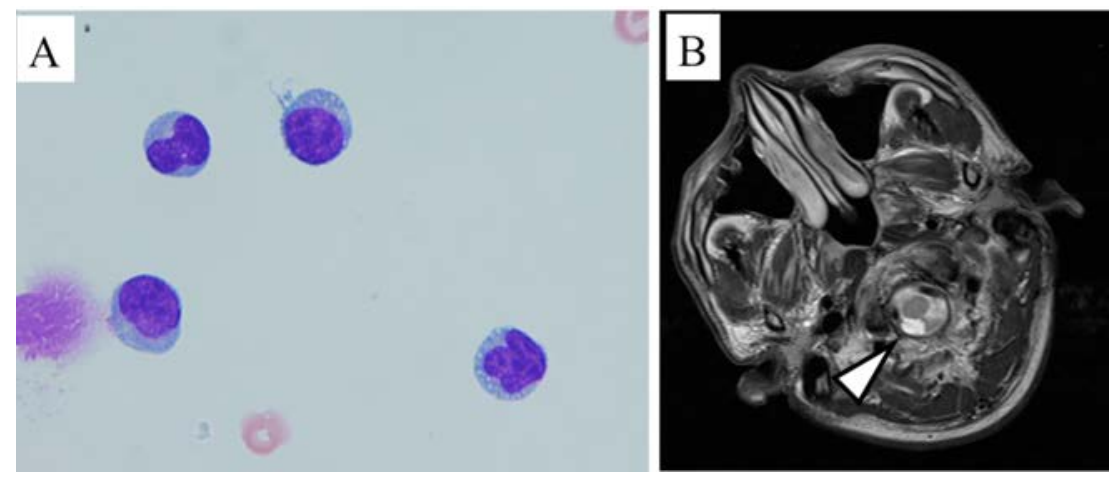

Figure 2. Several plasma cells were observed in the cerebrospinal fluid of our patients (A). T1-weighted gadolinium contrast-enhanced magnetic resonance imaging showed an intrathecal tumor with a high signal intensity around the medulla oblongata $(B$, arrowheads). 
CNS recurrence, we administered pomalidomide $4 \mathrm{mg}$ /day on days 1-21, with 20 $\mathrm{mg}$ of dexamethasone weekly for each 28day cycle. ${ }^{11}$ After the two cycles, our patient developed grade 4 neutropenia. Subsequently, a reduced dose of $2 \mathrm{mg}$ was administered for 2 cycles, but grade 4 neutropenia occurred again. He resumed pomalidomide at $1 \mathrm{mg}$ and continued the low dose without severe hematological abnormalities. Twelve months after the CNS relapse, both enhanced CT and brain MRI with Gd enhancement revealed no extramedullary tumors. In our outpatient follow-up, he maintained VGPR without major complications for more than 18 months after the diagnosis of CNS relapse.

\section{Discussion}

The prognosis of plasma cell disorder has improved following the introduction of new agents and the development of SCT, but a cure remains elusive. The long-term survival rate of PPCL is low due to the aggressive nature of the disease that comprises high tumor burden and extramedullary involvement. In the US, median overall survival of PPCL was 12 months in 2006-2009. ${ }^{4}$ Upfront allo-SCT is still one of the treatment options for young PPCL patients without major complications. In our study, we performed upfront allo-SCT with a myeloablative-conditioning regimen for our young patients without major complications. The Center for International Blood and Marrow Transplant Research (CIBMTR) conducted a retrospective SCT study in PPCL, and demonstrated high survival rates in an autologous group compared with those in an allogeneic group. ${ }^{6}$ In the CIBMTR study, non-relapse mortality in the allogeneic group was much higher at 3 years $(42 \% v s .5 \%)$, despite this group possessing a lower relapse rate $(39 \%$ vs. $61 \%$ ). Our patient survived for more than 2 years after allo-SCT, although he unfortunately suffered from CNS relapse on day 350. Consolidation and maintenance therapy after auto- and/or allo-SCT in plasma cell disorder is still controversial. However, some clinical trials have recently shown that lenalidomide maintenance after auto-SCT for MM significantly prolonged progression-free survival (PFS) and overall survival. ${ }^{12-14}$ Moreover, a prospective clinical trial by the Intergroupe Francophone du Myélome group showed that a bortezomibbased regimen followed by auto-SCT and subsequent maintenance therapy with lenalidomide, bortezomib, and dexamethasone for PPCL significantly improved PFS compared with those who received a reduced intensity conditioning allograft. ${ }^{7}$ In the future, auto-SCT and maintenance therapy combined with novel agents may be a treatment option for young PPCL patients.

The prognosis of plasma cell disorders with CNS involvement is extremely poor. In a retrospective study on CNS myeloma conducted in 12 Greek institutions, there was no significant difference in median survival of CNS myeloma (called post CNS-MM) between novel drug-treated patients and those given other treatments (4 months vs. 2 months). ${ }^{15}$ By multivariable analysis, extramedullary lesions, prior to treatment with novel drugs, and high LDH levels at myeloma diagnosis were statistically independent predictors of post CNS-MM survival. These findings corroborate our observations that our patient with CNS relapse of PPCL had an extremely short-term outcome. The frequency of CNS involvement is high among PPCL patients. It has been reported that $19 \%$ of post CNS-MM patients met the criteria for PPCL. ${ }^{15}$ Furthermore, some of these PPCL patients developed isolated CNS relapse during systemic remission after auto-SCT. ${ }^{8,9,15}$ In a prospective study by Royer et al., 2 PPCL patients experienced neuromeningeal relapse after autologous- and allo-SCT, respectively, and both patients soon died despite intrathecal chemotherapy. ${ }^{7}$ In the present case, although VGPR was maintained by RVD induction therapy followed by allo-SCT, isolated CNS relapse occurred within 1 year.

Several drugs used in multiple myeloma, including bortezomib and lenalidomide, do not efficiently cross the bloodbrain barrier (BBB). ${ }^{15}$ Meanwhile, IMiDs such as thalidomide and pomalidomide effectively penetrate the BBB. ${ }^{15-17}$ Of note, $\mathrm{BBB}$ penetration of lenalidomide was $11 \%$ in a rhesus monkey model, whereas that of thalidomide was $42 \% .{ }^{16}$ In a murine model, pomalidomide displayed 39\% BBB penetration and high anti-tumor activity in the CNS. ${ }^{17}$ To the best of our knowledge, the anti-tumor effect of thalidomide is inferior to that of pomalidomide. ${ }^{18}$ Additionally, pomalidomide is more effective in ameliorating extramedullary involvement. ${ }^{19,20}$ In our case, concurrent IT and RT followed by $\mathrm{Pd}$ was initiated after the diagnosis of isolated CNS involvement after allo-SCT. In addition, maintenance therapy by $\mathrm{Pd}$ might prolong survival to prevent systemic recurrence, including CNS involvement, for more than 18 months. The role of pomalidomide for PPCL patients with CNS involvement should be further explored in clinical trials.

\section{Conclusions}

Our PPCL patient received RVD induction therapy followed by up-front allo-SCT. His relapse involved the CNS, predicting an extremely poor outcome. However, concurrent IT and RT followed by pomalidomidebased maintenance therapy well controlled his CNS recurrence and prolonged his survival. To find an optimal treatment for this rare but aggressive PPCL, prospective clinical trials for this disorder should take into account the importance of myeloma drug penetration across the $\mathrm{BBB}$ in order to enhance the treatment of CNS recurrence.

\section{References}

1. Fernandez de Larrea C, Kyle RA, Durie $\mathrm{BG}$, et al. Plasma cell leukemia: consensus statement on diagnostic requirements, response criteria and treatment recommendations by the International Myeloma Working Group. Leukemia 2013;27:780-91.

2 Dimopoulos MA, Palumbo A, Delasalle KB, Alexanian R. Primary plasma cell leukaemia. Br J Haematol 1994;88:7549.

3. Tiedemann RE, Gonzalez-Paz N, Kyle RA, et al. Genetic aberrations and survival in plasma cell leukemia. Leukemia 2008;22:1044-52.

4. Gonsalves WI, Rajkumar SV, Go RS, et al. Trends in survival of patients with primary plasma cell leukemia: a population-based analysis. Blood 2014;124: 907-12.

5. Pagano L, Valentini CG, De Stefano V, et al. Primary plasma cell leukemia: a retrospective multicenter study of 73 patients. Ann Oncol 2011;22:1628-35.

6. Mahindra A, Kalaycio ME, Vela-Ojeda $\mathrm{J}$, et al. Hematopoietic cell transplantation for primary plasma cell leukemia: results from the Center for International Blood and Marrow Transplant Research. Leukemia 2012;26:1091-7.

7. Royer B, Minvielle S, Diouf M, et al. Bortezomib, Doxorubicin, cyclophosphamide, dexamethasone induction followed by stem cell transplantation for primary plasma cell leukemia: a prospective phase II study of the Intergroupe Francophone du Myélome. J Clin Oncol 2016;34:2125-32.

8 Fassas AB, Muwalla F, Berryman T, et al. Myeloma of the central nervous system: association with high-risk chromosomal abnormalities, plasmablastic morphology and extramedullary manifestations. Br J Haematol 2002;117: 
103-8.

9. Eskelund CW, Andersen NF. Localized relapse of primary plasma cell leukaemia in the central nervous system. Case Rep Hematol 2015;2015: 273565 .

10. Tamura S, Koyama A, Shiotani C, et al. Successful bortezomib/dexamethasone induction therapy with lenalidomide in an elderly patient with primary plasma cell leukemia complicated by renal failure and pulmonary hypertension. Intern Med 2014;53:1171-5.

11. Mele G, Coppi MR, Guaragna G, Spina A. Response to pomalidomide plus fixed low-dose dexamethasone in a case of secondary plasma cell leukemia. Leuk Res 2016;40:30-2.

12. Palumbo A, Cavallo F, Gay F, et al. Autologous transplantation and maintenance therapy in multiple myeloma. $\mathrm{N}$
Engl J Med 2014;371:895-905.

13. Attal M, Lauwers-Cances V, Marit G, et al. Lenalidomide Maintenance after Stem-Cell Transplantation for Multiple Myeloma. N Engl J Med 2012;366:1782-91.

14. McCarthy PL, Owzar K, Hofmeister $\mathrm{CC}$, et al. Lenalidomide after stem-cell transplantation for multiple myeloma. N Engl J Med 2012;366:1770-81.

15. Katodritou E, Terpos E, Kastritis E, et al. Lack of survival improvement with novel anti-myeloma agents for patients with multiple myeloma and central nervous system involvement: the Greek Myeloma Study Group experience. Ann Hematol 2015;94:2033-42.

16. Muscal JA, Sun Y, Nuchtern JG, et al. Plasma and cerebrospinal fluid pharmacokinetics of thalidomide and lenalidomide in nonhuman primates. Cancer
Chemother Pharmacol 2012;69:943-7.

17. Jiang Y, Wang J, Rozewski DM, et al. Sensitive liquid chromatography/mass spectrometry methods for quantification of pomalidomide in mouse plasma and brain tissue. J Pharm Biomed Anal 2014;88:262-8.

18. Andhavarapu S, Roy V. Immunomodulatory drugs in multiple myeloma. Expert Rev Hematol 2013;6:69-82.

19. Short KD, Rajkumar SV, Larson D, et al. Incidence of extramedullary disease in patients with multiple myeloma in the era of novel therapy, and the activity of pomalidomide on extramedullary myeloma. Leukemia 2011;25:906-8.

20. Mussetti A, Dalto S, Montefusco V. Effective treatment of pomalidomide in central nervous system myelomatosis. Leuk Lymphoma 2013;54:864-6. 